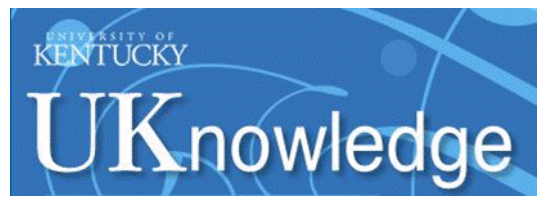

University of Kentucky

UKnowledge

Educational, School, and Counseling

Psychology Faculty Publications

Educational, School, and Counseling

Psychology

3-2014

\title{
Parenting Styles and Adjustment Outcomes Among College Students
}

Keisha M. Love

University of Kentucky, klove20@kennesaw.edu

Deneia M. Thomas

Eastern Kentucky University

Follow this and additional works at: https://uknowledge.uky.edu/edp_facpub

Part of the Counseling Psychology Commons, Educational Psychology Commons, and the Student Counseling and Personnel Services Commons

Right click to open a feedback form in a new tab to let us know how this document benefits you.

\section{Repository Citation}

Love, Keisha M. and Thomas, Deneia M., "Parenting Styles and Adjustment Outcomes Among College Students" (2014). Educational, School, and Counseling Psychology Faculty Publications. 1.

https://uknowledge.uky.edu/edp_facpub/1

This Article is brought to you for free and open access by the Educational, School, and Counseling Psychology at UKnowledge. It has been accepted for inclusion in Educational, School, and Counseling Psychology Faculty Publications by an authorized administrator of UKnowledge. For more information, please contact UKnowledge@lsv.uky.edu. 


\section{Parenting Styles and Adjustment Outcomes Among College Students}

Digital Object Identifier (DOI)

http://dx.doi.org/10.1353/csd.2014.0013

\section{Notes/Citation Information}

Published in Journal of College Student Development, v. 55, no. 2, p. 139-150.

( 2014 The Johns Hopkins University Press. This article first appeared in Journal of College Student Development, Volume 55, Issue 2, March, 2014, pages 139-150. 


\title{
Parenting Styles and Adjustment Outcomes Among College Students
}

\author{
Keisha M. Love Deneia M. Thomas
}

Research has demonstrated that parenting styles partially explain college students' academic adjustment. However, to account for academic adjustment more fully, additional contributors should be identified and tested. We examined the fit of a hypothesized model consisting of parenting styles, indicators of well-being, and academic adjustment among 315 college students. The model demonstrated a close fit to the data and contained several significant paths.

A plethora of research has demonstrated that parenting styles are pivotal to college students' academic adjustment (Dornbusch, Ritter, Leiderman, Roberts, \& Fraleigh, 1987; Hickman, Bartholomae, \& McKenry, 2000; Joshi, Ferris, Otto, \& Regan, 2003; Strage \& Brandt, 1999). Academic adjustment refers to students' ability to cope effectively with the demands of their academic work and their level of academic achievement (Baker \& Siryk, 1999). In general, researchers have demonstrated that an authoritative parenting style, which is characterized by high levels of love, support, and discipline, tends to yield greater academic adjustment than other types of parenting styles such as the permissive (high love, low discipline) or authoritarian style (low love, high discipline; Baumrind, 1971; Boveja, 1998; Spera, 2005). Despite the wealth of studies linking parenting styles to academic outcomes for college students, a major limitation associated with this literature is that parenting styles only explain a small portion of academic adjustment, typically less than 20\% (Bean, Bush, McKenry, \& Wilson, 2003; Hickman et al., 2000). This finding indicates that factors beyond parenting styles should be examined to account for academic adjustment more comprehensively.

For instance, parenting styles have been associated with adjustment outcomes such as psychological well-being and emotional well-being (Lockett \& Harrell, 2003; Mounts, 2004), and these factors have been shown to contribute to academic adjustment. Therefore, well-being may be the cognitive and/ or emotional mechanism that mediates the relationship between parenting styles and academic adjustment, but this assertion has yet to be fully examined. We sought to advance the literature pertaining to students' academic adjustment by investigating the fit of a hypothesized model comprised of parenting styles, emotional well-being, self-esteem, and academic adjustment. In addition, we tested the relationship between parenting styles and well-being as key predictors of academic adjustment to determine if the inclusion of indicators of well-being would account for more variance in the relationship between parenting styles and academic adjustment among college students.

\section{OVERVIEW OF PARENTING STYLES}

The primary role of parents is to influence, teach, and control their children (Baumrind, 1971). This control revolves around two

Keisha M. Love is Chair of the Department of Educational, School, and Counseling Psychology at the University of Kentucky. Deneia M. Thomas is Associate Professor of Counseling and Educational Psychology at Eastern Kentucky University. 
components of parenting: responsiveness and demandingness (Maccoby \& Martin, 1983). Responsiveness is described as warmth or supportiveness, which refers to the extent to which parents intentionally cultivate their children's individuality, self-regulation strategies, and assertiveness by giving attention, providing support, and responding to particular concerns, needs, and demands. Parental demandingness is expressed as the behavioral control and the expectations put on their children to become a part of the family by the parents' rules, supervision, and disciplinary practices.

The Baumrind Parenting Styles premise is based on Baumrind's (1971) extensive analysis of three parenting archetypes: authoritarian, permissive, and authoritative. Authoritarian parents tend to value high levels of discipline and restriction, and to withhold positive affection from their child. Conversely, permissive parents make few demands on, seldom establish rules for, minimize discipline of, and show high positive affection and nurturance towards their child. Authoritative parents are in the middle of the authoritarian-permissive continuum, providing high levels of positive affection and nurturance, while disciplining their children with established rules, providing structure, maintaining expectations, and encouraging autonomy.

\section{Parenting Styles and Academic Adjustment}

Parenting styles are important because they have been associated with critical developmental outcomes including social, psychological, and emotional well-being, cognitive development, and academic adjustment (Baumrind, 1971; Boveja, 1998; Deater-Deckard, Dodge, Bates, \& Petit, 1996; Grolnick \& Ryan, 1989; Kochanska, Murray, \& Coy, 1997; Mounts, 2004; Prelow, Bowman, \& Weaver, 2007; Silva, Dorso, Azhar, \& Renk, 2007; Steinberg, Elmen,
\& Mounts, 1989). In general, researchers' findings have indicated that students whose parents ascribe to parenting practices aligned with the authoritative parenting style tend to report greater academic adjustment (Hickman et al., 2000; Turner, Chandler, \& Heffer, 2009). Hickman et al. (2000) demonstrated that the authoritative parenting style was positively related to college students' academic adjustment. Furthermore, the researchers demonstrated that students whose parents were supportive and actively involved in their adolescent's educational endeavors and conveyed the importance of education to their young adult tended to have greater academic success (Epstein \& Dauber, 1991; AbdulAdil \& Farmer, 2006). Among a sample of adolescents, Prelow et al. (2007) found that parental support, involvement, and warmth was predictive of higher grades in English/ language arts, mathematics, science, and history/social science. Trusty (2002) found parent involvement and support predicted emerging adults' academic expectations, which in turn was related to academic performance.

Parenting Styles, Well-Being, and Academic Adjustment

Although parenting styles contribute to academic adjustment, they only account for a small portion of academic adjustment. Therefore, additional factors that can account for academic adjustment more fully should be explored. As mentioned previously, parenting styles have also been associated with psychological and emotional well-being, and researchers have concluded that well-being is predictive of academic adjustment. For instance, positive indicators of well-being such as self-esteem are associated with increased academic adjustment (Hickman et al., 2000). Therefore, to gauge academic adjustment outcomes comprehensively, indicators of wellbeing should also be examined as contributors of these outcomes. 
Emotional well-being, also referred to as subjective well-being, relates to life satisfaction, positive affect, and the absence of negative affect (Ryan \& Deci, 2001). Emotional well-being is often operationalized through measures of life satisfaction, anxiety, depression, or a combination of all three, which is considered a global indicator of emotional well-being. Psychological well-being relates to personal growth, self-acceptance, and self-actualization; it is often operationalized as self-esteem and happiness (Lent, 2004; Ryan \& Deci, 2001). For the purposes of this study, and consistent with the literature, we operationalized emotional well-being as a global indicator comprised of life satisfaction, depression, anxiety, and stress (Baker \& Siryk, 1999; Christopher, 1999; Lent, 2004); we operationalized psychological well-being as self-esteem, hereafter referred to as self-esteem.

Chapell and Overton (2002) found selfesteem and GPA were moderately correlated among a sample of college students $(r=.51$, $p<.001)$. Similarly, self-esteem has been positively associated with academic adjustment (Friedlander, Reid, Shupak, \& Cribbie, 2007). Moreover, Prichard and Wilson (2003) found that students with low levels of self-esteem were significantly more likely to consider dropping out of college than students who reported high levels of self-esteem. Depression has also been shown to affect students' academic adjustment negatively. For example, Haines (1996) found that students who were depressed demonstrated greater academic difficulties due to a lack of motivation, concentration, and energy. As a result, these students demonstrated poorer academic performance (grade point averages) than students who demonstrated no depressive symptoms. Likewise, among a sample of diverse college students, Hysenbegasi, Hass, and Rowland (2005) found that students who were mildly to moderately depressed reported a 0.49 -point decrease in their GPA versus students who reported no depressive symptoms. Mounts (2004) found an authoritative parenting style to be linked to lower levels of depression and loneliness among late adolescent college students. Similarly, Silva et al. (2007) found fathers' authoritative parenting behaviors decreased anxiety, while mothers' authoritarian parenting behaviors increased anxiety among a sample of college students. Authoritative parenting behaviors have been associated with reports of high self-esteem, and permissive and authoritarian parenting behaviors have been associated with reports of low self-esteem (Bean et al., 2003; Carlson, Uppal, \& Prosser, 2000; Garber, Robinson, \& Valentiner, 1997;

Gecas \& Schwalbe, 1986). Clearly, well-being is related to academic adjustment; however, a comprehensive examination of parenting styles and well-being as predictors of academic adjustment has yet to be conducted among emerging adults who are college students.

\section{PURPOSE AND RESEARCH HYPOTHESES}

We sought to advance the literature related to college students' academic adjustment by examining the fit of a hypothesized model composed of parenting styles, emotional well-being, self-esteem, and academic adjustment among college students. Given the relationship among the above-mentioned variables, we predicted that the model would demonstrate a close fit to the data (Hypothesis 1). Furthermore, we predicted that significant paths would be found within our model. Specifically, we expected parenting styles (authoritarian, authoritative, and permissive) to predict self-esteem and emotional well-being (Hypothesis 2). In addition, we hypothesized that self-esteem and emotional well-being would predict academic adjustment (Hypothesis 3). 


\section{METHOD \\ Participants}

Participants were 315 college students from a community college $(8.9 \%)$, a predominately White university (28.5\%), and 2 historically Black universities (50.0\%) in the Eastern and Southern United States (12.6\% of participants did not report the institution they were attending). All universities were public institutions. Roughly $52.0 \%$ of participants were Black / African American, 39.6\% White, 2.2\% biracial, 1.9\% Asian American, $1.9 \%$ other, $1.2 \%$ international, and $0.3 \%$ Latino. The large representation of African Americans in the sample is likely a function of our recruitment from 2 historically Black universities. The majority of students were young women $(71.2 \%)$, and averaged 20.68 years of age $(S D=2.58)$. Participants did not vary by age, parental income, personal income, or sex as a function of university type. All undergraduate classes were represented: freshmen (22.8\%) and sophomores (39.6\%) collectively represented $62.4 \%$ of the sample; juniors and seniors comprised $19.0 \%$ and $17.1 \%$ of the sample, respectively. The self-reported average annual participant income was $\$ 9,369$; participants reported an average annual parental household income of $\$ 107,120$. The majority of participants grew up in either a two-parent household with their biological/adoptive parents (57.3\%), or a single-parent household with a biological/ adoptive parent (27.8\%). Grandparent households $(6.0 \%)$, stepfamily households $(5.7 \%)$, and foster homes $(1.0 \%)$ represented the remaining household types identified; not all participants indicated their family type.

\section{Measures and Procedures}

Participants completed a self-report, demographic questionnaire that solicited information such as race, sex, class rank, parental income, personal income, household type, and university type. In addition, participants completed 4 survey questionnaires to assess the constructs of interest, namely parenting styles, emotional well-being, self-esteem, and academic adjustment.

Parenting Styles. The authors measured parenting styles using the 30-item Parental Authority Questionnaire (PAQ; Buri, 1991). The PAQ measures three styles of parenting (authoritarian, permissive, and authoritative) according to Baumrind's conceptualization of parenting styles and requires participants to retrospectively reflect on their parents' parenting practices. As such, the PAQ contains three subscales, each consisting of 10 items. Respondents rate their agreement with statements regarding parenting behaviors using a 5-point Likert scale ranging from 1 (strongly disagree) to 5 (strongly agree). We scored subscales by averaging across items; higher mean scores represent a greater adherence to the behaviors associated with a given parenting style, with the highest mean score of the three subscales representing parents' primary parenting style. The reliability coefficients demonstrated adequate internal consistency for scores within each subscale in the current sample of students: authoritarian $(\alpha=.72)$, authoritative $(\alpha=.73)$, and permissive $(\alpha=$ .82). Buri (1991) provided evidence of adequate convergent validity by examining the extent to which scores on the PAQ correlated with a measure of parental nurturance. Pearson bivariate correlations ranged from -.53 to +.56 and were in the expected direction. Coefficient alphas ranged from .74 to .87 , demonstrating evidence of internal consistency.

Emotional Well-Being. Emotional wellbeing was measured using the 15 -item Personal-Emotional subscale of the Student Adaptation to College Questionnaire (SACQ; Baker \& Siryk, 1999). The SACQ is a 67-item self-report measure used to assess adjustment 
to college along four dimensions, including academic, social, emotional, and institutional attachment. The Personal-Emotional subscale, 15 items, serves as a global indicator of emotional functioning by assessing items related to anxiety, depression, physical wellbeing, and stress. Respondents rated items according to a Likert-type scale ranging from 1 (applies very closely to me) to 9 (doesn't apply to me at all); the subscale was scored by averaging across items. The tabulation of the scores signifies that higher means are indicative of emotional well-being, whereas lower scores are indicative of emotional distress. Adequate criterion-related validity, convergent validity, and reliability coefficients (alpha ranging from .81 to .95 ) for the scale have been established in previous samples of college students (Baker \& Siryk, 1999). The coefficient alpha for scores on the Personal-Emotional subscale in our sample was .75.

Self-Esteem. We measured self-esteem using the Global subscale of the Self-Esteem Questionnaire (SEQ; Dubois, Felner, Brand, Phillips, \& Lease, 1996). The SEQ is a 42 -item self-report questionnaire designed to measure individuals' sense of worth and acceptance in six domains: school, family, body image, sports/athletics, and global worth. The Global Self-Esteem subscale measures individuals' overall thoughts of self-worth and acceptance. Participants rate their level of agreement with statements using a 4-point Likert-type scale from 1 (strongly disagree) to 4 (strongly agree). We calculated scores for each subscale by averaging items: higher mean scores represented higher levels of self-esteem in each specified area. The construct validity of the SEQ was demonstrated through an exploratory factor analysis in which factor loadings ranged from .27 to .90 (Dubois et al., 1996). Further evidence was provided through a confirmatory factor analysis (comparative fix index equaled .92). The coefficient alphas for subscale scores ranged from .81 to .92 . The alpha coefficient for participants' scores in this study was .86 .

Academic Adjustment. We measured academic adjustment using the Academic Adjustment subscale of the SACQ (Baker \& Siryk, 1999). The 24-item Academic Adjustment subscale measures students' success in coping with various educational demands and their ability to excel academically, which encompasses their GPA and class performance. Items are anchored on a Likert-type scale ranging from 1 (applies very closely to me) to 9 (doesn't apply to me at all). We scored the subscale by averaging across items: higher scores represented greater academic adjustment. Criterion validity has been established for the SACQ through significant correlations observed between the four SACQ subscales and counseling-seeking behaviors, attrition rates, and academic performance among first-year university students. Baker and Siryk (1999) reported Cronbach's alphas for the SACQ subscales scores ranging from .82 to .94 among college students. The alpha coefficient for scores on the Academic Adjustment subscale in our sample was .84 .

\section{Procedures}

After obtaining Institutional Review Board approval, we solicited participants at each university from several departments including business, psychology, education, sociology, and political science. Instructors were asked for permission to recruit participants directly from their classes. On a date specified by the instructors, trained research assistants (graduate students) visited each class and read a standardized solicitation script that provided a general overview of the study, detailed the voluntary nature of the study, discussed the risks and benefits associated with the study, and explained incentives for participation. The research assistants also fielded questions from potential participants prior to agreeing 


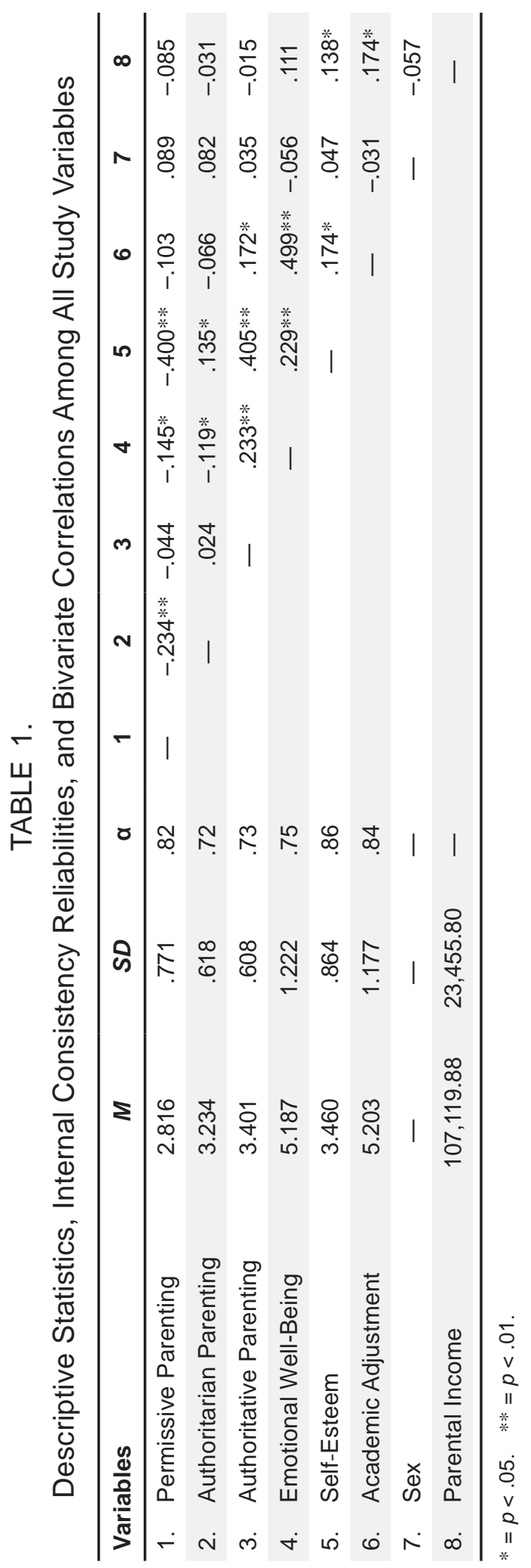

to participate in the study. Survey materials, several self-report questionnaires, were distributed and completed in the classrooms. Across the four institutions, approximately $80 \%$ of students completed and returned the survey. We awarded two $256 \mathrm{~K}$ USB drives through a random drawing in each classroom as an incentive to participate.

\section{RESULTS}

This descriptive, correlational survey study utilized structural equation modeling to test the research hypotheses. Structural equation modeling allows researchers to test complex models of prediction, such as when multiple predictors and mediators are present in a model, as is the case in the current study. It also allows researchers to test relationships among variables beyond what can be tested using multiple regression (Kelloway, 1998). To test our hypotheses, we used AMOS 18.0 structural equation modeling software (Arbuckle, 2009) to test the fit of our hypothesized model and to check for significant path coefficients among our variables of interest. Using maximum likelihood estimation, which tends to be precise, we evaluated the adequacy of the model-to-data fit based upon examinations of the chi-square statistic and several other indices, including the comparative fit index (CFI), the Tucker Lewis coefficient (TLI) and the root mean square error of approximation (RMSEA; McDonald \& Ho, 2002). The better our model fit the data, the more accurate our predictions about the relationship between the predictors, mediators, and criterion. A nonsignificant chisquare statistic $(p>.05)$, which is desirable, indicates a close fit of the model to the data, as this nonsignificance indicates that the model does not vary significantly from the data. In addition, a RMSEA value less than .05 paired with CFI and TLI values greater than .95 represents a close fit of the model 
to the data. Table 1 contains the correlations and descriptive statistics of all study variables.

The results of the hypothesized path model are in Figure 1. As previously mentioned, we examined several fit indices to determine if our hypothesized model fit the data. We hypothesized that the model would demonstrate a close fit to the data (Hypothesis (1). As predicted, the fit indices demonstrated a very close model-to-data fit: $\chi^{2}(04, n=315)=4.053, p=.399, \mathrm{CFI}=1.00$, $\mathrm{TLI}=.99, \mathrm{RMSEA}=.00,90 \% \mathrm{CI}=.00, .08$; our proposed model accurately and adequately reflected patterns in the data, lending support for Hypothesis 1. Specifically, parenting practices explained $25 \%$ of the variance in selfesteem and $8 \%$ of the variance in emotional well-being, providing support for our second hypothesis, which was that parenting styles would predict self-esteem and emotional wellbeing. Last, in Hypothesis 3, we predicted that self-esteem and emotional well-being would predict academic adjustment. This hypothesis was partially supported, as only emotional well-being significantly predicted academic adjustment.
Given the close fit of our model, we sought to interpret the model by examining significant paths found within (which are indicative of a significant relationship between variables). Significant paths were demonstrated between permissive parenting and self-esteem: critical ratio $(\mathrm{cr})=-7.738, p<.001$, standardized regression weight $=.374$; participants whose parents were permissive in nature tended to report low levels of self-esteem, as evidenced by the negative critical ratio. These individuals also tended to experience low levels of emotional well-being, or rephrased, high levels of emotional distress $(\mathrm{cr}=-2.993, p<.01$; standardized regression weight $=.171$ ), as a significant negative path was demonstrated between permissive parenting and emotional well-being. Similarly, individuals whose parents were authoritarian in their parenting style reported low levels of emotional well-being ( $\mathrm{cr}=-2.876, p<.05$, standardized regression weight $=.164)$; a significant negative path was found between authoritarian parenting and emotional well-being. Conversely, an authoritative parenting style demonstrated a significantly positive influence on self-esteem

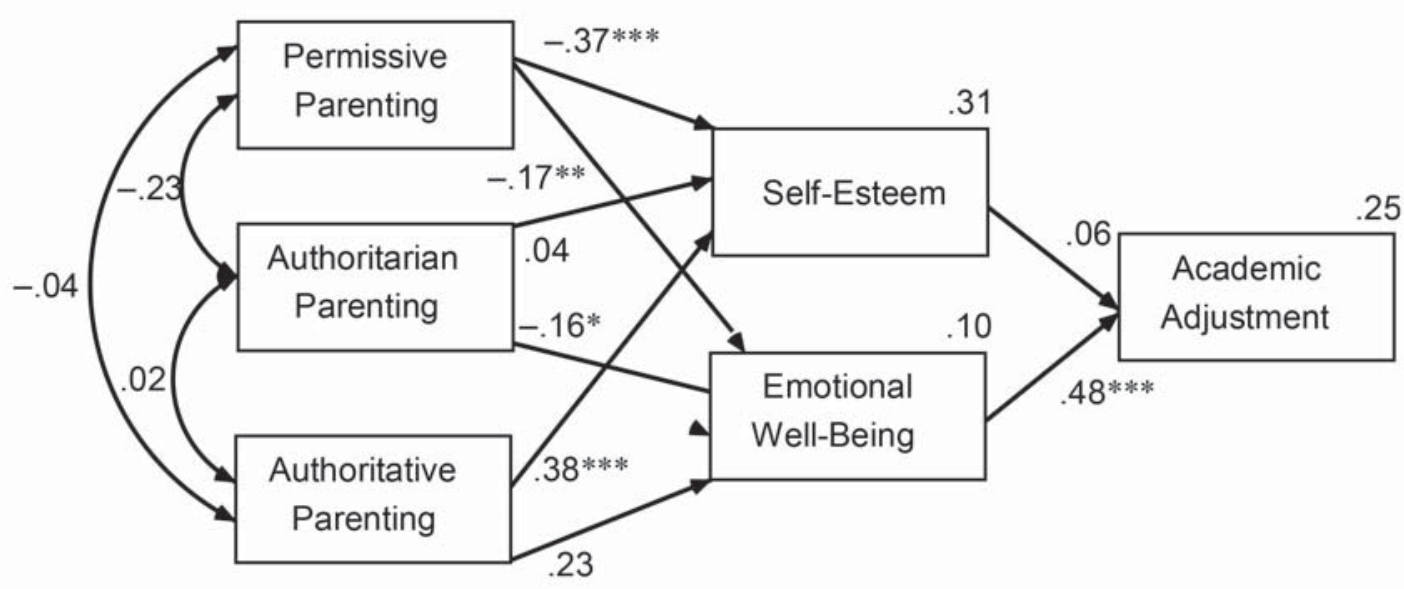

FIGURE 1. Results of the Hypothesized Path Model

Note. All reported regression weights are standardized.

$* p<.05 . \quad * * p<.01$. *** $p<.001$. 
$(\mathrm{cr}=4.148, p<.001$, standardized regression weight $=.388)$; these individuals tended to report high levels of self-esteem. Last, a significant path emerged between emotional well-being and academic adjustment $(\mathrm{cr}=9.526, p<.001$, standardized regression weight $=.486$ ), with individuals who reported high levels of emotional well-being also reporting high levels of academic adjustment.

Given the possibility that the influence of parenting styles on academic adjustment was only partially mediated by self-esteem and well-being, we tested an alternative model in which direct paths from permissive, authoritarian, and authoritative parenting were drawn directly to academic adjustment. The fit indices demonstrated a marginal modelto-data fit: $\chi^{2}(01, n=316)=3.318, p=.069$, $\mathrm{CFI}=.99, \mathrm{TLI}=.79$, RMSEA $=.86,90 \%$ $\mathrm{CI}=.00, .195$; we concluded that the revised model did not fit as close as our original model. Furthermore, the direct paths between permissive, authoritative, and authoritarian parenting to academic adjustment were all insignificant $(p>.05)$. As a result, we concluded that our original model depicting full mediation was the most accurate and parsimonious explanation of the data.

\section{DISCUSSION}

In an effort to identify new variables that should be explored in conjunction with parenting styles when predicting academic adjustment, and in an attempt to explain academic adjustment more fully among college students, we examined a model that consisted of parenting styles, emotional well-being, self-esteem, and academic adjustment. Our findings identified additional empirically tested variables, psychological and emotional wellbeing, that are vital contributors to students' academic adjustment. Several important findings emerged from the test of our model.
First, given the close fit of our model to the data, it is clear that parenting practices covary with self-esteem, well-being, and academic adjustment in early adulthood. While the inclusion of indicators of well-being only explained an additional $5 \%$ of the variance in academic adjustment over similar studies in the literature, these variables did emerge as significant indicators and were an improvement over past studies. Furthermore, now that these variables have been identified, future studies can begin examining similar variables (e.g., anxiety, resilience, life satisfaction) that may account for even more variance.

This study reveals that a permissive parenting style predicted self-esteem and emotional well-being, with this type of parenting style being associated with low levels of self-esteem and emotional well-being, which is consistent with other researchers' findings (Shucksmith \& Glendinning, 1995). Likewise, an authoritarian parenting style predicted low levels of emotional well-being, indicating that these individuals tended to experience greater amounts of emotional distress; however, individuals whose parents endorsed an authoritative parenting style experienced high levels of self-esteem. Studies have shown that comparing permissive and authoritarian parenting styles, an authoritative approach tends to be associated with greater positive outcomes across several psychosocial domains, such as emotional well-being, academic adjustment, social adjustment, and prosocial behaviors (Silva et al., 2007). Last, as predicted, emotional well-being predicted academic adjustment. Students who were emotionally healthy and experienced minimal levels of emotional distress tended to report high levels of academic adjustment.

\section{Implications of Findings}

Developmentally, college students typically complete the process of separating and 
differentiating themselves from their parental figures, taking greater control and personal responsibility for their lives, and assuming new adult roles and responsibilities (Crede $\&$ Niehorster, 2012). However, the latest generation of college students, such as the ones in our sample, the Millennials (born 1982-2002), have a set of characteristics and experiences that have made their collegiate experience different from preceding generations. Such differences have created the need for administrators and faculty to make adjustments to serve this generation of students effectively (Coomes \& DeBard, 2004). For instance, from a parenting perspective, Millennials have been socialized to feel special by their parents, particularly those with authoritative parents. This sense of being special is great for facilitating self-esteem, as was demonstrated in this study, but can be problematic for academic professionals when Millennials expect academic professionals to cater to them and treat them special.

Millennials have also been characterized as being overly dependent on their parental figures, which can retard the developmental transition from dependent child to autonomous adult. This overdependence often translates into overdependence on faculty and administrators (DeBard, 2004). A delicate balance should be practiced between providing students with guidance while encouraging independent thought and problem solving. In this study, permissive parenting behaviors were associated with both low self-esteem and low emotional well-being; thus, fostering or encouraging dependence may have adverse outcomes for students.

Last, Millennials tend to be confident in their academic abilities and are high achievers, yet they tend to only be interested in doing the minimum to achieve success (DeBard, 2004), which can create dissonance. For example, we found that students with authoritative parents reported high self-esteem scores, but this esteem was not directly related to their academic adjustment. Perhaps other mediating factors such as motivation should be examined in combination with parenting styles, self-esteem, self-efficacy, and academic outcomes to understand the relation among these variables more fully.

As it relates to emotional adjustment and academic adjustment, students with low self-esteem and low levels of emotional well-being (i.e., high emotional distress) had academic difficulties; therefore, addressing academic deficiencies and problems directly can be a first step toward positive change for these students. Academic advisors and instructors can help students utilize support resources such as peer tutoring or individual and group sessions with teaching/graduate assistants as one way to improve their academic achievement. In addition, given the significant associations between self-esteem, emotional well-being, and academic adjustment, parents, advisors, and instructors should collaborate with mental health professionals on campus to focus on building students' self-esteem and improving emotional well-being as an added method to improving academic adjustment. Counseling interventions should focus on improving and strengthening communication and interactions with parental figures as a way to facilitate greater adjustment among students. Identifying and repairing problematic behavioral patterns and emotional issues may facilitate the successful attainment of other developmental competencies (e.g., developing romantic relationships, establishing secure peer relationships, developing or solidifying career goals, and achieving academic success; Mattanah, Lopez, \& Govern, 2011).

Instructors, residence life directors and assistants, and administrators who may observe students suffering from emotional distress or low self-esteem should make referrals to the 
campus counseling center as an additional way to address academic difficulties that the students may be experiencing, or may be about to experience. In addition, through outreach efforts such as hosting seminars and workshops conducted in residence halls, distributing informational handouts at sporting events, or launching an awareness campaign during Mental Health Awareness Week, mental health professionals should educate students about the signs of emotional distress and low self-esteem, and explain the impact that both may have on their academic performance. Nevertheless, most important, practitioners should give students information about getting assistance for these concerns.

\section{Limitations and Directions for Future Research}

Due to the descriptive nature of data collected in this study, causality cannot be assumed. For example, although significant relationships were demonstrated between parenting styles, well-being, and academic adjustment, we can only assert that these variables are associated. It is also important to note that the participants in our study were college students primarily from middle class households that were afforded the opportunity to attend college. The results of this study may not necessarily generalize to individuals of the same age from other economic classes, or students not at the postsecondary level; therefore, we recommend that the model be tested with different samples, such as those from different socioeconomic backgrounds and educational statuses. In addition, for further understanding, the fit of the model should be tested between groups on demographic factors such as sex and institutional type to determine if the relationships hold for males and females and those at historically Black colleges and universities, community colleges, and predominately-White universities.

In addition, although the sample size was sufficient to support the path analysis conducted, others should replicate this study with a larger sample. It is possible that other paths approaching significance, such as the path between authoritative parenting and emotional well-being, will reach significance with increased power. We recommend reconstructing the model using indicators of emotional well-being and academic adjustment that are not from the same measure. Our emotional well-being subscale and academic adjustment subscale demonstrated a weak, but significant, correlation, which means that a small portion of the relationship between emotional well-being and academic adjustment may be a function of shared variance between the subscales. It would be beneficial for future researchers to select separate indicators of emotional well-being and academic adjustment to provide further support for the results found in the current study. Last, longitudinal studies should be conducted to provide further support for our model and to demonstrate the association of the variables at different developmental points in time for students.

Correspondence concerning this article should be addressed to Keisha M. Love, University of Kentucky, Department of Educational, School, and Counseling Psychology, 245 Dickey Hall, Lexington, KY 40506; Keisha.Love@uky.edu 


\section{REFERENCES}

Abdul-Adil, J., \& Farmer, A. (2006). Inner-city African American parental involvement in elementary schools: Getting beyond urban legends of apathy. School Psychology Quarterly, 21, 1-12. doi:10.1521\%2Fscpq.2006.21.1.1

Arbuckle, J. (2009). Amos 18.0. Chicago, IL: Small Waters.

Baker, R., \& Siryk, B. (1999). Student adaptation to college questionnaire. Los Angeles, CA: Western Psychological Press.

Baumrind, D. (1971). Current patterns of parental authority. Developmental Psychology, 4, 261-267. doi:10.1037/ h0030372

Bean, R., Bush, K., McKenry, P., \& Wilson, S. (2003). The impact of parental support, behavioral control, and psychological control on the academic achievement and self-esteem of African American and European American adolescents. Journal of Adolescent Research, 18, 523-541. doi:10.1177/0743558403255070

Boveja, M. (1998). Parenting styles and adolescents' learning strategies in the urban community. Journal of Multicultural Counseling and Development, 26, 110119. doi:10.1002/j.2161-1912.1998.tb00191.x

Buri, J. (1991). The Parental Authority Questionnaire. Journal of Personality Assessment, 57, 110-119. doi:10.1207/ s15327752jpa5701_13

Carlson, C., Uppal, S., \& Prosser, E. (2000). Ethnic differences in processes contributing to the self-esteem of early adolescent girls. Journal of Early Adolescence, 20, 44-67. doi: $10.1177 / 0272431600020001003$

Chapell, M., \& Overton, W. (2002). Development of logical reasoning and the school performance of African American adolescents in relation to socioeconomic status, ethnicity, and self-esteem. Journal of Black Psychology, 28, 295-317. doi: $10.1177 / 009579802237539$

Christopher, J. (1999). Situating psychological well-being: Exploring the cultural roots of its theory and research. Journal of Counseling and Development, 77, 141-152. doi: 10.1002/j.1556-6676.1999.tb02434.x

Deater-Deckard, K., Dodge, K., Bates, J., \& Petit, G. (1996). Physical discipline among African American and European American mothers: Links to children's externalizing behaviors. Developmental Psychology, 32, 1065-1072. doi:10.1037/0012-1649.32.6.1065

Coomes, M., \& DeBard, R. (2004). A generational approach to understanding students. New Directions for Student Services, 106, 5-16. doi: $10.1002 /$ ss. 121

Crede, M., \& Niehorster, S. (2012). Adjustment to college as measured by the Student Adaptation to College questionnaire: A quantitative review of its structure and relationships with correlates and consequences. Educational Psychology Review, 24, 133-165. doi:10.1007/s10648-011-9184-5

DeBard, R. (2004). Millennials coming to college. New Directions for Student Services, 106, 33-45.

Dornbusch, S., Ritter, P., Leiderman, P., Roberts, D., \& Fraleigh, M. (1987). The relation of parenting style to adolescent school performance. Child Development, 58, 1244-1257. doi: $10.2307 / 1130618$
Dubois, D., Felner, R., Brand, S., Phillips, R., \& Lease, M. (1996). Early adolescent self-esteem: A developmentalecological framework and assessment strategy. Journal of Research on Adolescence, 6, 543-579.

Epstein, J., \& Dauber, S. (1991). School programs and teacher practices of parent involvement in inner-city elementary and middle schools. Elementary School Journal, 93, 289-305. doi:10.1086/461656

Friedlander, L., Reid, G., Shupak, N., \& Cribbie, R. (2007). Social support, self-esteem, and stress as predictors of adjustment to university among first-year undergraduates. Journal of College Student Development, 48, 259-274. doi:10.1353/csd.2007.0024

Garber., J., Robinson, N., \& Valentiner, D. (1997). The relation between parenting and adolescent depression: Self-worth as a mediator. Journal of Adolescent Research, 12, 12-33. doi:10.1177/0743554897121003

Gecas, V., \& Schwalbe, M. (1986). Parental behavior and adolescent self-esteem. Journal of Marriage and the Family, 48, 37-46. doi:10.2307/352226

Grolnick, W., \& Ryan, R. (1989). Parenting styles associated with children's self-regulation and competence in school. Journal of Educational Psychology, 81, 143-154. doi: 10.1037/0022-0663.81.2.143

Haines, M. (1996). The effects of depressed mood on academic performance in college students. Journal of College Student Development, 37, 519-526.

Hickman, G., Bartholomae, S., \& McKenry, P. (2000). Influence of parenting style on the adjustment and academic achievement of traditional college freshmen. Journal of College Student Development, 41, 41-54.

Hysenbegasi, A., Hass, S., \& Rowland, C. (2005). The impact of depression on the academic productivity of university students. Journal of Mental Health Policy and Economics, $8,145-151$

Joshi, A., Ferris, J., Otto, A., \& Regan, P. (2003). Parenting styles and academic achievement in college students. Psychological Reports, 93, 823-828. doi: 10.2466/pr0.2003.93.3.823

Kelloway, E. K. (1998). Using LISEREL for structural equation modeling: A researcher's guide. Thousand Oaks, CA: SAGE.

Kochanska, G., Murray, K., \& Coy, K. (1997). Inhibitory control as a contributor to conscience in childhood: From toddler to early school age. Child Development, 68, 263-277. doi: $10.2307 / 1131849$

Lent, R. (2004). Toward a unifying theoretical and practical perspective on well-being and psychosocial adjustment. Journal of Counseling Psychology, 51, 482-509. doi:10.2466/ PR0.93.7.823

Lockett, C., \& Harrell, J. (2003). Racial identity, self-esteem, and academic achievement: Too much interpretation, too little supporting data. Journal of Black Psychology, 29, 325336. doi:10.2466/PR0.93.7.823

Maccoby, E., \& Martin, A. (1983). Socialization in the context of the family: Parent-child interaction. In P. H. Mussen (Ed.) \& E. M. Hetherington (Vol. Ed.), Handbook of child psychology: Vol.4. Socialization, personality, and social development (4th ed., pp. 1- 101). New York, NY: Wiley. 
Mattanah, J., Lopez, F., \& Govern, J. (2011). The contributions of parental attachment bonds to college student development and adjustment: A meta-analytic review. Journal of Counseling Psychology, 58, 565-596.

McDonald, R., \& Ho, M. (2002). Principles and practice in reporting structural equation analyses. Psychological Methods, 7, 64-82. doi: 10.1037//1082-989X.7.1.64

Mounts, N. (2004). Contributions of parenting and campus climate to freshmen adjustment in a multiethnic sample. Journal of Adolescent Research, 19, 468-491. doi:10.2466/ PR0.93.7.823

Prelow, H., Bowman, M., \& Weaver, S. (2007). Predictors of psychosocial well-being in urban African American and European American youth: The role of ecological factors. Journal of Youth and Adolescence, 36, 543-533.

Prichard, M., \& Wilson, G. (2003). Using emotional and social factors to predict student success. Journal of College Student Development, 44, 18-28.

Ryan, R., \& Deci, E. (2001). On happiness and human potentials: A review of research on hedonic and eudaimonic well-being. Annual Review of Psychology, 52, 141-166.

Shucksmith, J., \& Glendinning, A. (1995). Models of parenting: Implications for adolescent well-being within different types of family contexts. Journal of Adolescence, 18, 253-270. doi:10.2466/PR0.93.7.823
Silva, M., Dorso, E., Azhar, A., \& Renk, K. (2007). The relationship among parenting styles experienced during childhood, anxiety, motivation, and academic success in college students. Journal of College Student Retention, 9, 149-167. doi: 10.2190/CS.9.2.b

Spera, C. (2005). Review of the relationship among parenting practices, parenting styles, and adolescent school achievement. Educational Psychology Review, 17, 125-146. doi:10.2466/ PR0.93.7.823

Steinberg, L., Elmen, J., \& Mounts, N. (1989). Authoritative parenting, psychosocial maturity, and academic success among adolescents. Child Development, 60, 1424-1436. doi: $10.23072 \mathrm{~F} 1130932$

Strage, A., \& Brandt, T. (1999). Authoritative parenting and college students' academic adjustment and success. Journal of Educational Psychology, 91, 146-156. doi:10.2466/ PR0.93.7.823

Trusty, J. (2002). African American's educational expectations: Longitudinal causal models for women and men. Journal of Counseling and Development, 80, 332-345. doi:10.1002/j.1556-6678.2002.tb00198.x

Turner, E., Chandler, M., \& Heffer, R. (2009). The influence of parenting styles, achievement motivation, and self-efficacy on academic performance in college students. Journal of College Student Development, 50, 337-346. doi:10.1353/csd.0.0073 